\title{
MEMORIAS EN PÚRPURA PASIONARIA. CARMEN MONDRAGÓN “NAHUI OLIN" Y GERARDO MURILLO “DR. ATL"
}

\author{
PURPLE PASSIONFLOWER MEMOIRS. CARMEN MONDRAGON VALSECA \\ "NAHUI OLIN" AND GERARDO MURILLO “DR. ATL"
}

Araceli Toledo Olivar

Benemérita Universidad Autónoma de Puebla

\section{Resumen:}

Carmen Mondragón Valseca (Nahui Olin), poeta, caricaturista y pintora de origen mexicano, sostuvo una relación amorosa con Gerardo Murillo, más conocido como el Dr. Atl. En Gentes profanas en el convento, Atl recrea, a través de cartas escritas por personajes ficticios, la relación sostenida con la poeta. El presente ensayo aborda el discurso amoroso de Pierre (Atl) y Eugenia (Nahui Olin) a través de la vena teórica de Julia Kristeva, Roland Barthes y Eugenio Trías.

Palabras clave:

Nahui Olin, Dr. Atl, Kristeva, Barthes, Trías

\section{Abstract:}

Carmen Mondragón Valseca (Nahui Olin) was a Mexican poet, a cartoonist and a painter. She had a romance with Gerardo Murillo, who was known as Dr. Atl. In Profane people in the convent, Atl recreates, through out letters written by fictional characters, the relationship that he had with the poet. Guided by the theoretical vein of Julia Kristeva, Roland Barthes and Eugenio Trías, this essay approaches the amorous speech of Pierre (Atl) and Eugenia (Nahui Olin).

\section{KeYwORDS:}

Nahui Olin, Dr. Atl, Kristeva, Barthes, Trías 
1893 es el año del nacimiento de Carmen Mondragón Valseca. Mujer de marcados claroscuros que se desempeó como poeta, caricaturista, pintora y modelo de desnudo artístico, en el escenario cultural vanguardista de la segunda década del siglo XX mexicano. Los padres de Carmen concibieron ocho vástagos en total; ella fue la quinta hija. La educación que Carmen y sus hermanos recibieron fue privilegiada, considerando el contexto social de la época, porque desde pequeños tuvieron contacto con las lenguas y culturas española y francesa. Carmen se mostró interesada en la literatura desde muy pequeña: exploró la escritura a través de la poesía, lo mismo en español que en francés. Así pues, Mondragón Valseca publicó: Óptica cerebral. Poemas dinámicos (1922), Calinement je suis dedans (1923), A dix ans sur mon pupitre (1924) y Energía cósmica (1937). Sobre la vida personal de Carmen, se sabe que ella estuvo casada con Manuel Rodríguez Lozano de 1913 a 1921. En el último año de su matrimonio, Carmen inició una sonada relación con el vulcanólogo Gerardo Murillo (Dr. Atl). Debe tenerse presente que la segunda década del siglo XX mexicano puede imaginarse como un escenario dominado por una atmósfera revolucionaria que, en esos momentos, dejaba atrás su faceta combativa, y en su lugar permitía la entrada de nuevas formas de pensamiento provenientes del exterior. Poco a poco, alusiones a Freud, Marx, Einstein, Picasso, al Dadaísmo y al Futurismo empiezan a volverse familiares en el círculo intelectual. En La cultura mexicana del siglo XX, Carlos Monsiváis señala que en el primer año de la década de los veinte no se presentan grandes avances relacionados con la producción artística, puesto que los creadores se encontraban supeditados a las influencias provenientes de la civilización europea. En este escenario marcado por la vida bohemia y la incipiente orientación de la poesía al sentido de sí misma, más allá de los velos de las convenciones literarias de la época o a lo que Octavio Paz denominaba la búsqueda de la palabra primigenia, se gestó el torbellino pasional que inspiró el apartado "Una historia de amor" de Gentes Profanas en el convento de Gerardo Murillo. En la obra en cuestión, Gerardo Murillo, famoso pintor, escritor y vulcanólogo mexicano, elaboró 63 apartados que van desde cartas, poemas, cuentos y hasta un relato fantástico. De manera particular, el capítulo "Una historia de amor" entreteje las cartas y poemas que los personajes Eugenia y Pierre intercambiaron en un espacio y tiempo ficcional a mediados del siglo XX. En esta investigación interesa estudiar el discurso amoroso presente en el capítulo previamente mencionado, a partir de la perspectiva teórica de Julia Kristeva (Historias de Amor), Roland Barthes (Fragmentos de un discurso amoroso) y Eugenio Trías (Tratado de la pasión). Debe hacerse notar que los poemas de la sección motivo de análisis son de la autoría de la poeta Carmen Mondragón Valseca (Nahui Olin). Se infiere, además, que la relación amorosa que ella sostuvo con Gerardo Murillo fue narrada y recreada a través de estas cartas. Por ello se entiende que el personaje de Eugenia corresponde a Nahui y el de Pierre a Gerardo. Los amantes de "Una historia de amor" entretejen mosaicos vivenciales signados por goces edénicos y por situaciones límite: dolorosas, punzantes, inquietantes para el alma del amante que busca reconocerse e imprimirse en el otro. Los enamorados, sin saberlo, se abren al mundo a partir de varios fractales, porque de acuerdo con lo referido por Kristeva en Historias de amor: "La experiencia amorosa une 
indisolublemente lo simbólico (lo prohibido, discernible, pensable), lo imaginario (lo que el Yo representa para sustentarse y agrandarse) y lo real (ese imposible donde los afectos aspiran a todo y adonde no hay nadie que tenga en cuenta el hecho de que yo no soy más que una parte)" (6). Perseguir la armonía mediante el engranaje fluído de estas tres dimensiones es un cometido arduo, puesto que, las percepciones generadas en el universo de los amantes son susceptibles de convertirse en ilusiones; esto es, en un oasis de exuberante atractivo, pero carente de firmeza.

La primera vez que Gerardo Murillo (Doctor Atl) y Carmen Mondragón Valseca (Nahui Olin) se vieron fue el 22 de Julio de 1921. En “Amarse como los dioses”, Tomás Zurián describe el encuentro:

El impacto anímico y erótico fue avasallador. Cuando más entusiasmado platicaba con algunos concurrentes las jugosas anécdotas de su siempre agitada vida, una aparición lo hizo volver la mirada: una mujer maravillosa bajaba las monumentales escaleras de la mansión. El Dr. Atl no era el único que se extasiaba ante aquella visión de belleza extrema; casi todas las miradas de los hombres - excepto la del marido - se habían concentrado en ese ser de rostro perfecto, de enormes ojos verdes y cuerpo ondulante y felino que regalaba generosamente, con sensualidad, cada uno de sus movimientos, como si los hubiera ensayado desde hacía miles de años. (Zurián 1992: 21)

Este pasaje es narrado por Pierre en "Una historia de amor". En él admite su fascinación por Eugenia y es consciente del vuelco que su vida está a punto de dar. Se sabe presa de los ojos de la enigmática mujer. Él se deja conducir sin voluntad por el canto hipnótico del fuego y a pesar de su incredulidad, se entrega: "Fulguró entre la multitud como una antorcha y mi espíritu se quemó en su llama como un insecto [...] ¿Cómo es posible que en un hombre como yo pueda encenderse una pasión con tanta violencia?" (Atl 1986: 86). Aferrarse a la imagen de la amada es inexorable, lo mismo que ceder al torbellino de aire caliente que impulsa el deseo. El espíritu ambiciona aquello que deleita su mirada; esto es una imagen, un ensueño, una aparición. Sobre tal certeza, Roland Barthes afirma en Fragmentos de un discurso amoroso: "En el campo amoroso, las más vivas heridas provienen más de lo que se ve que de lo que se sabe" (Barthes 1998: 172). La imagen alimenta la actitud compulsiva del enamorado, el deseo se duele con aquello que escapa al dominio de la mirada. Pierre no es la excepción. Con el correr de los días, su desasosiego y con ello su dolor por la ausencia de la imagen adorada, crece. Finalmente, sin necesidad de una espera larga, coincide con Eugenia y su marido en la Alameda Central. Como resultado de ese encuentro, los tres convienen en verse en casa de Pierre, con la intención de que la pareja tuviera la oportunidad de apreciar las propuestas artísticas del segundo. Eugenia acudió sola a la cita. Posiblemente ese día se tome como el inicio de la intensa y tormentosa relación protagonizada por Pierre/Atl y Eugenia/Nahui, tanto en la esfera ficcional como en la real. En Las siete cabritas, Elena Poniatowska reflexiona: “Así le dijo la serpiente a Eva y así empezó el paraíso para ambos. ¡Pobre Nahui! ¡Pobre del Dr. Atl! Vulcanólogo, vulcanizado. Su vulcana rugía más que Iztaccíhuatl. Inflamada no dormía más. 
Se quejaba, pedía más. Sus escurrimientos no eran lava, eran fuego. Sus fulgores venían de otro mundo" (Poniatowska 2000: 71). Conforme el lector se adentra en "Una historia de amor" se percata de la insistencia de Eugenia por mostrar la superioridad de su inteligencia, en función de la entrega desbordada con el ser amado. Esta apuesta, de acuerdo con lo aseverado en líneas anteriores por Poniatowska, es una suerte de prisión. Eugenia afirma:

Como un vaso conteniendo un gas que se agranda y aumenta su volumen hasta que se oprime contra las paredes que lo guardan, así siento que mi inteligencia crece cada día, a cada instante, a cada segundo; pero pronto se siente oprimida bajo una fuerza que es la existencia de mi ser; sin embargo, se siente superior a esta fuerza que debe despreciar, y es en realidad más poderosa que el universo, más grande que el infinito [...] Nuestro espíritu vuela siempre hacia el ser que nos comprende; su espíritu siente las mismas impresiones, sufre las mismas confusiones [...] (Atl 1950: 113-114)

El ser enamorado aspira al sentimiento de unión y consumación. Empresa complicada, sin duda; tal vez inalcanzable. Pero, no debe dejarse de lado que tan ambiciosa aspiración, aunque imposible de lograr, no deja de ser el sueño hedonista por excelencia. Es el delirio de los sentidos. La asimilación gaseosa de los cuerpos mediante la temperatura adecuada. Así el volcán naciente conformado por nuestros protagonistas. Eugenia subraya en sus cartas la urgencia de un espíritu que intenta fundirse con el del ser amado en un entorno ajeno a esta realidad. La escritura es uno de los espacios que consagran la pasión de los amantes. Pierre exclama: “[...] Escribir desorbitadamente como si viviera en otros mundos. Fuera del amor, ella está sumergida en los misterios del cosmos y a ellos me arrastra" (Atl 1950: 93). Se observa que el sentimiento amoroso reconfigura la existencia de la pareja, porque de acuerdo con Julia Kristeva:

El amor es el tiempo y el espacio en el que el «yo» se concede el derecho a ser extraordinario [...] Además del deseo, más allá o más acá del placer, el amor los rodea y los desplaza para elevarme a las dimensiones del universo [...] Espacio dilatado, infinito, donde desde mis desfallecimientos evoco, por intermedio del ser amado, una visión ideal. ¿La mía? ¿La suya? ¿La nuestra? Imposible y, sin embargo, mantenida. (Kristeva 2006: 4)

Las cartas escritas por Pierre y Eugenia muestran los puntos álgidos de su relación, tanto los afortunados como los que son testimonio de su degradación. Durante el inicio de la relación esta comunicación epistolar es un juego que permite a los amantes la asimilación e inserción de cada emoción y estado anímico en el universo que ambos comparten en común a través de la escritura. La carta, asimismo, está conformada por una estructura: "Dialéctica particular [...] a la vez vacía (codificada) y expresiva (cargada de ganas de significar el deseo)" (Barthes 1998: 60). Es decir, se invoca en el papel la presencia del ser amado porque, evocando a Freud, cuando se piensa en alguna persona es porque se le ha olvidado. Este incesante olvidar y 
recordar conforman una dinámica circular, porque: "Muchas cosas, por asociación, te recuerdan en mi discurso. "Pensar en ti" no quiere decir otra cosa que esa metonimia" (Barthes 1998: 60). El espacio deshabitado de la memoria, simulando al mar, acoge y aleja la impresión del ser amado. Eugenia se muestra angustiada y desconsolada cuando ella y Pierre dejan de verse por unos días: "Pierre, Pierre estoy desesperada — loca por tu ausencia—, algo me empuja a huir, a huir siempre y para siempre porque no puedo soportar este dolor [...] Todos los días espero tus noticias y todos los días permanecen vacíos de vida y de esperanza, mi corazón empieza a debilitarse, como si se le extrajeran constantemente gotas de sangre" (Atl 1950: 96-97). El personaje femenino se muestra vulnerable e incapaz de controlar su turbación. El dolor se entremezcla con notas de miedo, ansiedad, agonía. El miedo debe reconocerse como una emoción compleja que en un primer momento obliga a Eugenia a escapar de sí misma, de su yo y, en un segundo nivel, la lleva más allá de los cercos impuestas por la norma. La transgresión como se observa, opera en dos dimensiones. El sueño del reencuentro con Pierre, puede entenderse, siguiendo a Kristeva, como una amalgama de:

Placer y promesa o esperanza [que] permanece en una especie de futuro perfecto. Es el no-tiempo del amor que, instante y eternidad, pasado y futuro, presente [...] colma y, sin embargo, [...] deja insatisfecha. Hasta mañana, hasta siempre, como siempre fiel, eternamente como antes, como cuando fue, como cuando haya sido, a ti... ¿Permanencia del deseo o de la decepción? (Atl 1950: 5)

En la urdimbre del amor entran en combinación una serie de elementos contradictorios. Una cara luminosa de este escenario presenta a los amantes gozando de los intercambios afectuosos y físicos que mutuamente engendran; sin embargo, la fachada turbia del amor llega a proyectar su tiranía cuando consigue doblegar las facultades racionales de la pareja. Esta manifestación es identificada como amor-pasión por el filósofo Eugenio Trías en El tratado de la pasión. El autor español, tomando como ejemplo la relación de Tristán e Isolda, explica en qué consiste la dupla amor-pasión. El patrón plantea una relación de reciprocidad signado por el mismo padecimiento, porque: "Sufren de una misma posesión passional [...] Amor Tirano que los tiene en sus manos, con absoluta entrega de su voluntad y con absoluta hipoteca de su libertad e independencia" (Trías 2006: 21). De manera que, de acuerdo con lo descrito por Trías, dichos amantes se encuentran cegados por un sentimiento que nubla sus sentidos. El mundo exterior importa poco a los seres que, enajenados, dirigen la experiencia amorosa a la muerte. En ese sentido, en "Una historia de amor" se vislumbra la intensificación del sentimiento amoroso a partir de la idea de finitud y posible trascendencia que circunda a la muerte. Hay una doble ligadura entre aquellos que son elegidos por Eros, puesto que sus almas son enaltecidas al hacerse merecedores de la posibilidad de vivir intensamente a través del encuentro con el otro, aunque al mismo tiempo, tal vivencia traiga consigo una trampa. La influencia de Eros es tal que, el corazón más duro se muestra vulnerable: el sufrimiento ocasionado por este encuentro es el más deseable de los tormentos. A través de las 600 cartas intercambiadas por Pierre y Eugenia 
se narra parte de la historia de un hombre y una mujer que cayeron presas de Eros, llevando su relación más allá de los límites de la razón. Se habla también de un estado de dicha que en ciertas ocasiones es interrumpido por los excesos de emociones desbordadas. Pierre declara:

Nuestra vida se ha vuelto tumultuosa - un torrente desbordado que desciende de la montaña, hecho de borbotones, de espumas espesas y de rumor de tumbostorrente que se remueve entre peñascales con potencia telúrica arrancando de cuajo los grandes árboles de mis ilusiones que un día se irguieron frondosos, $\mathrm{y}$ arrastrando con furia cuanto encuentra a su paso. Los celos han azotados su corazón. Y al mío también. (Atl 1950: 101)

La violencia ocasionada por los celos de Eugenia carcome y debilita su relación con Pierre con el correr de los días. Gritos, balazos, cartas públicas y privadas formaron parte de la antesala que vaticinó el trágico desenlace de la relación. Los amantes protagonizaban los escándalos del momento cuando se encontraban en la calle y Eugenia, lejos de controlar su ira, se dejaba consumir por ese fuego. Las riñas y los encuentros desafortunados no cesaban, lo mismo que las cartas de amor impregnadas de reclamos, amenazas y arrepentimiento. Empero, es una sola voz la que expresa dicha tortura: la de Eugenia. Las palabras escritas de Pierre se diluyen y paralela a su extinción, fenece el idilio.

\section{CONSIDERACIONES FINALES}

En Una historia de amor, las emociones y sentimientos más extremos se conjugan para configurar un romance punzante, esquivo a la razón y de llama debocada. Así lo percibe Pierre en Eugenia: "En muchas de estas cartas hay un profundo deseo de venganza, un odio a la vida, una insatisfacción manifiesta, espiritual y corporal. Su última, sobre todo, revela, que «tiene prisa de irse de este mundo», y dado el temperamento de esta maravillosa criatura, ¿no es lógico suponer que haya querido llevarse a su lado al hombre que tanto amó?" (Atl 1950: 133). El apartado analizado culmina con la hipotética muerte de Eugenia y Pierre. Quien narra la historia se deshace en suposiciones trágicas sobre la muerte de la pareja, y en cómo las cartas que relatan su historia fueron colocadas en un espacio particular del convento que presenció juramentos de amor eterno, riñas y reconciliaciones. La voz narrativa, asimismo, reconstruye en su mente el eco luminoso de la silueta de Eugenia, testigo fantasmal de la desventura amorosa. Con la intención de establecer un paralelismo entre ficción y realidad, debe mencionarse que el claustro de la Merced (lugar en el cual vivía el Dr. Atl) presenció el idilio amoroso del Dr. Atl y Nahui Olin. En ese contexto ellos llegaron a intercambiar más de 200 cartas. Papeles en los cuales se juraron amor eterno, tal y como lo hicieron Pierre y Eugenia. Asimismo, la relación entre Atl y Nahui agonizó de una manera similar a la de los personajes creados por Atl en Gentes profanas en el convento. Había comentado en líneas anteriores que los personajes construidos por el Dr. Atl exploran el amor a través de situaciones extrapoladas; algo similar ocurre a un nivel emocional. La exaltación e idealización del ser amado es visible en el discurso de ambos 
personajes, particularmente al incio de la relación. Sin embargo, en el ocaso del romance, es Eugenia quien hace patente su frustación a través del odio, del desprecio por Pierre. Julia Kristeva ejemplifica este doble vínculo a partir de la famosa historia de Romeo y Julieta: “[... ] Es Julieta la que encuentra las fórmulas más intensas para indicar que este amor está sostenido por el odio [...] parece tratarse de un odio en el mismo origen del entusiasmo amoroso. De un velo preexistente al velo de la idealización amorosa" (197). Odio y amor forman una estructura cuyas piezas son complicadas de discernir. Se pensaría, siguiendo una secuencia lógica, que es el amor el que antecede al odio cuando se habla de romance; pero, a partir de lo expuesto por Kristeva, se vislumbra con claridad la presencia germinal del odio en el amor. Visto de esta manera: el odio puede llegar a ser el cauce natural del amor. Pierre y Eugenia, al igual que Romeo y Julieta, son los vehículos de un cúmulo de emociones y sentimientos asociados a aquello que el otro refleja de uno mismo, aquello que nos resulta familiar, por hacer referencia al talante amoroso, a la fase eufórica de la relación. El odio se hace visible cuando se empieza a ver al otro como si fuera un extranjero: "En la relación con un objeto, con otro, el odio, dice Freud, es más antiguo que el amor. Desde que el otro me parece diferente a mí, me es extraño, repelido, repelente, abyecto: odiado" (Kristeva 198). En el caso de "Una historia de amor", el desgaste ocasionado por las constantes peleas de la pareja puede tomarse como la antesala del extrañamiento al cual hace referencia Kristeva: la familiaridad que antaño fuera reconfortante se ha vuelto en contra de Pierre y Eugenia. Por último, debo decir que la muerte de los amantes (Pierre y Eugenia), por mano propia (suicidio), como lo sugiere la cita con la que inicio este apartado, a los ojos de Barthes resuena así: "En el campo amoroso, el deseo del suicidio es frecuente: una pequeñez lo provoca" (263). La muerte de los amantes deja ver la fragilidad de la vida, así como la del amor. Aunque, paradójicamente, la muerte, desde un punto de vista romántico, también contempla la trascendencia del amor a través de la muerte. Este tipo de acontecimiento es, siguiendo a Kristeva, una suerte de extensión del delirio amoroso, la unión en penumbras de los amantes, de Pierre y Eugenia, en una posterior comunión fantasmal.

\section{REFERENCIAS BIBLIOGRÁFICAS}

Barthes, Roland. Fragmentos de un discurso amoroso. México, Siglo XXI, 1998, pp. 5 - 172. Dr. Atl. Gentes profanas en el convento. México, Ediciones Botas, 1950, pp. 86 - 133.

Chevalier, Jean y Gheerbrant Alain. Diccionario de los símbolos. Barcelona, Herder editorial, 1986, pp. 398

Kristeva, Julia. Historias de amor. México, Siglo XXI, 2006, pp.4.

Lopátegui, Rosas. Nahui Olin sin principio ni fin. Vida, obra y varia invención. México: Universidad Autónoma de Nuevo León, 2011.

Malvido, Adriana. Nahui Olin. La mujer del sol. México, Edivisión, 1999, pp. 39 - 49. 
Mondragón, Carmen (Nahui Olin). Óptica cerebral (Poemas dinámicos). México, Ediciones México Moderno, 1922.

. Calinement. Je suis dedans. México, Librería Guillot, 1923.

. A dix ans sur mon pupitre. México, Cultura, 1924.

. Nahui Olin. México, Imprenta Moderna, 1927.

. Energía cósmica. México, Botas, 1937.

Monsivais, Carlos. La cultura mexicana en el siglo XX. México, El Colegio de México, 2010.

Poniatowska, Elena. Las siete cabritas. México, Era, 2000, pp. 71.

Toledo, Araceli y Alejandro Palma. “Las inquietudes espirituales: cuerpo y poesía de Nahui Olin". Confluencias en México. Palabra y género. Puebla, BUAP y Smith Collegue, 2007, pp. 253-267.

Toledo Olivar, Araceli. En el ensueño del caleidoscopio. Teresa Wilms Montt y Nahui Olin. México, Facultad de Filosofía y Letras BUAP, 2018.

Trías, Eugenio. El tratado de la pasión. España, Debolsillo, 2006, pp. 21.

Zurián, Tomás. Nahui Olin Una mujer de los tiempos modernos. México, INBA, 1992, pp. $21,92$.

Zurián, Tomás y Rosario Cabrera. Rosario Cabrera: la creación entre la impaciencia y el olvido. México, Instituto Nacional de Bellas Artes, 1998

.Catálogo exposición Nahui olin Museo mural Diego

Rivera. México, INBA-CONACULTA, 2000. 